\title{
Biocompatibility of chitosan-coated iron oxide nanoparticles with osteoblast cells
}

\author{
This article was published in the following Dove Press journal: \\ International Journal of Nanomedicine \\ 24 October 2012 \\ Number of times this article has been viewed
}

\author{
Si-Feng Shi' \\ Jing-Fu Jia ${ }^{2}$ \\ Xiao-Kui Guo ${ }^{3}$ \\ Ya-Ping Zhao ${ }^{2}$ \\ De-Sheng Chen' \\ Yong-Yuan Guo' \\ Tao Cheng' \\ Xian-Long Zhang' \\ 'Department of Orthopedic Surgery, \\ Shanghai Sixth People's Hospital, \\ School of Medicine, ${ }^{2}$ School of \\ Chemistry and Chemical Technology, \\ ${ }^{3}$ Department of Medical Microbiology \\ and Parasitology, School of Medicine, \\ Shanghai Jiao Tong University \\ Shanghai, China
}

Correspondence: Xian-Long Zhang Department of Orthopedic Surgery, Shanghai Sixth People's Hospital, School of Medicine, Shanghai Jiao Tong University, 600 Yi Shan Road, Xu Hui District, Shanghai 200233, China

$\mathrm{Tel}+86216436918$

Fax +862 I 6470136

Email zhangxianlong20I0I@163.com
Background: Bone disorders (including osteoporosis, loosening of a prosthesis, and bone infections) are of great concern to the medical community and are difficult to cure. Therapies are available to treat such diseases, but all have drawbacks and are not specifically targeted to the site of disease. Chitosan is widely used in the biomedical community, including for orthopedic applications. The aim of the present study was to coat chitosan onto iron oxide nanoparticles and to determine its effect on the proliferation and differentiation of osteoblasts.

Methods: Nanoparticles were characterized using transmission electron microscopy, dynamic light scattering, $\mathrm{x}$-ray diffraction, zeta potential, and vibrating sample magnetometry. Uptake of nanoparticles by osteoblasts was studied by transmission electron microscopy and Prussian blue staining. Viability and proliferation of osteoblasts were measured in the presence of uncoated iron oxide magnetic nanoparticles or those coated with chitosan. Lactate dehydrogenase, alkaline phosphatase, total protein synthesis, and extracellular calcium deposition was studied in the presence of the nanoparticles.

Results: Chitosan-coated iron oxide nanoparticles enhanced osteoblast proliferation, decreased cell membrane damage, and promoted cell differentiation, as indicated by an increase in alkaline phosphatase and extracellular calcium deposition. Chitosan-coated iron oxide nanoparticles showed good compatibility with osteoblasts.

Conclusion: Further research is necessary to optimize magnetic nanoparticles for the treatment of bone disease.

Keywords: chitosan-coated iron oxide, magnetic nanoparticles, osteoblasts

\section{Introduction}

Osteoporosis is characterized by low bone mass and microarchitectural deterioration of bone tissue, with a subsequent increase in bone fragility and susceptibility to fracture. ${ }^{1}$ Osteoporosis currently affects 10 million Americans and is responsible for more than 1.5 million fractures annually, including hip, vertebral (spinal), wrist, and other fractures. ${ }^{2}$ The financial impact of osteoporosis is substantial, with annual direct medical costs estimated at \$17-\$20 billion in the US alone. ${ }^{2}$ Aging of the population is expected to increase the prevalence of osteoporosis and the number of osteoporotic fractures. ${ }^{3}$

The overall aim of treatment for osteoporosis prior to a fracture is to increase bone strength and reduce the risk of fracture. The anabolic agent, parathyroid hormone, and its analogs have been used to treat postmenopausal women with osteoporosis. ${ }^{4-6}$ Calcitonin and vitamin D have also shown some efficacy in reducing the risk of fractures. Hormone replacement therapy and the bisphosphonate, etidronate, have also 
been reported to reduce the risk of fracture, but these studies are less rigorous. ${ }^{7}$ In their lifetime, 30\%-50\% of women and $15 \%-30 \%$ of men will suffer a fracture related to osteoporosis. ${ }^{7}$ In most cases, surgical intervention to repair the fracture is required. Decreased bone mineral density creates difficulties relating to fracture reduction and fixation, as well as healing.

Low bone density is not limited to osteoporosis. Other conditions, such as loosening of a prosthesis after arthroplasty, are also caused by bone loss locally to the periprosthetic due to increased osteoclast activity and decreased osteoblast activity.

Although the therapies discussed may have some effect on low bone density, a limitation is the inability of most of these agents such as bisphosphonates to increase bone growth. ${ }^{8}$ Bisphosphonates have even been shown to decrease the proliferation of osteoblasts. ${ }^{8,9}$ Therefore, effective bone-building strategies will benefit patients with these conditions.

Iron oxide nanoparticles are the most commonly used magnetic nanoparticles and their use shows promise in a number of biomedical applications. The use of magnetic nanoparticles for delivery of orthopedic drugs is also promising. When an external magnetic field and field gradient are applied, active ingredients bound to or incorporated in these particles are successfully carried to the desired site with relatively high accuracy, minimum surgical intervention, maximum dose, and avoidance of toxic side effects on other organs. ${ }^{10-12}$

Chitosan is a deacetylated derivative of chitin, a natural polymer found in the shells of crustaceans, and is structurally similar to hyaluronic acid (extracellular matrix). ${ }^{13,14}$ The biomedical applications of chitosan have been studied for over 40 years. ${ }^{13}$ The excellent properties of chitosan, including its biocompatibility, bioactivity, biodegradability, and nontoxic byproducts make it easy to functionalize for biomedical applications. ${ }^{13,15}$ Previous research has shown that chitosan supports the growth of osteoblasts. ${ }^{13}$ Recently, the applications of chitosan in tissue engineering and drug delivery systems have been investigated. ${ }^{16}$ Chitosan films, gels, and porous sponge-like scaffolds have shown potential in regenerative medicine. ${ }^{15,17}$ A thin-film chitosan coating enhanced osteoblast growth on titanium substrates. ${ }^{16}$ Chitosan as a composite with calcium phosphate and hydroxyapatite was used to coat a titanium substrate due to its good biocompatibility. ${ }^{16}$

Although the osteogenic properties of chitosan in tissue engineering applications have been established, ${ }^{14}$ there are to our knowledge no reports of the use of magnetic chitosan nanoparticles in orthopedic disease or of chitosan-coated iron oxide nanoparticles as a magnetic transport carrier. Due to the promise shown by chitosan-coated magnetic nanoparticles in the field of orthopedics, we investigated the interactions of chitosan-coated iron oxide nanoparticles with osteoblasts in terms of their possible application for treatment of orthopedic diseases, including osteoporosis, prosthetic loosening, and many other diseases.

The aim of this study was to determine the cytocompatibility properties of chitosan-coated iron oxide nanoparticles with osteoblasts. The data suggest that osteoblast proliferation and differentiation increased in the presence of chitosancoated iron oxide nanoparticles in vitro.

\section{Materials and methods Preparation of chitosan-coated and uncoated iron oxide nanoparticles}

Iron oxide nanoparticles were prepared in an aqueous medium by addition of $5 \mathrm{~mL}$ ferric chloride $(0.25 \mathrm{M})$ to $5 \mathrm{~mL}$ ferrous sulfate solution $(0.25 \mathrm{M})$ and mixing. The solution was stirred constantly for 20 minutes under a nitrogen atmosphere at $45^{\circ} \mathrm{C}$ to remove any dissolved oxygen. Ammonia $(1 \mathrm{M}, 40 \mathrm{~mL}$ ) was then added and the mixture was stirred constantly for a further 30 minutes until a precipitate formed. This precipitate was washed four times with deionized water to remove excess ammonia, leaving a brown precipitate. The solution was mixed continuously and chitosan $0.2 \mathrm{mg} / \mathrm{mL}$ was added. The $\mathrm{pH}$ was adjusted to 4.0 using phosphoric acid. The solution was stirred constantly for a further 12 hours. The nanoparticles were then separated using a permanent magnet and washed four times with deionized water. The precipitate was directly dried in a vacuum oven at $50^{\circ} \mathrm{C}$ for 20 hours. The dried sample was sterilized by autoclaving prior to use.

\section{Nanoparticle characterization}

The size and shape of the iron oxide nanoparticles were characterized using a transmission electron microscope (TEM). A droplet of an aqueous dispersion of nanoparticles was placed on a TEM copper grid, allowed to dry, and examined under a Philips CM-120 TEM. Particle size distribution was measured using the dynamic light scattering technique (Malvern Zetasizer Nano, Worcestershire, UK). Iron oxide nanoparticles were dispersed in double-distilled water by sonication at $25^{\circ} \mathrm{C}$. A 2.42 refractive index and an absorbance of 0.2 were used for size measurements. The same apparatus was used to measure zeta potentials. X-ray diffraction was performed on dried nanoparticle powders 
using a Siemens D500 (Siemens, Berlin, Germany) within a $2 \theta$ range of $20-80$ degrees using $\mathrm{Cu} \mathrm{K} \alpha$ radiation. The magnetic properties of the dried nanoparticles were evaluated using vibrating sample magnetometry (LakeShore 7040, Westerville, $\mathrm{OH}$ ) at room temperature.

\section{Cell culture}

Human osteoblasts (SV40, American Type Culture Collection, Manassas, VA) were incubated under standard cell culture conditions $\left(37^{\circ} \mathrm{C}\right.$, humidified, $5 \% \mathrm{CO}_{2} / 95 \%$ air environment) in Dulbecco's modified Eagle's medium and nutrient mixture F12 (Dulbecco's modified Eagle's medium/ F12 medium, Gibco, Grand Island, NY), supplemented with $10 \%$ fetal bovine serum (Hyclone, Logan, UT) and 1\% penicillin/streptomycin.

\section{Interaction of osteoblasts with nanoparticles under TEM}

The SV40 human osteoblasts were incubated with chitosancoated and uncoated iron oxide nanoparticles $100 \mathrm{mg} / \mathrm{mL}$ to study the uptake of the nanoparticles into osteoblasts. After 48 hours, the cells were washed twice with phosphate-buffered solution and detached using $0.25 \%$ trypsin, washed and fixed with $2 \%$ glutaraldehyde for 2 hours, and then washed twice with phosphate-buffered solution. After treatment with $1 \%$ osmium tetroxide, the samples were dehydrated in a graded alcohol series $(25 \%, 50 \%, 75 \%, 95 \%$, and 100\%) and infiltrated with epoxy resin. The cells were then centrifuged and the pellets were transferred into the epoxy resin. After 48 hours of curing in an oven at $60^{\circ} \mathrm{C}$, the samples were sliced using a microtome. Thin sections were stained with uranylacetate and lead citrate for examination by TEM (CM-120, Philips, The Netherlands).

\section{Prussian blue staining of magnetic nanoparticles in cells}

Intracellular iron oxide was visualized by Perls' Prussian blue staining. In brief, after incubation with nanoparticles for 24 hours, the cells were washed with phosphate-buffered solution to remove free nanoparticles. Osteoblasts were fixed for 30 minutes in $4 \%$ paraformaldehyde. The cells were then washed with phosphate-buffered solution and incubated with potassium hexacyanoferrate solution (4\% potassium ferrocyanide $/ 6 \% \mathrm{HCl}, 1: 1 \mathrm{v} / \mathrm{v}$, Sigma, St Louis, MO) for 30 minutes. The cells were counterstained with $0.02 \%$ neutral red (Sigma), and observed under an inverted optical microscope. ${ }^{18-21}$

\section{Osteoblast proliferation}

Osteoblast proliferation tests were conducted after one, 3, and 6 days. Cells were grown in a 12-well plate at a density of 4000 cells $/ \mathrm{cm}^{2}$ in the presence of chitosan-coated and uncoated iron oxide nanoparticles $100 \mu \mathrm{g} / \mathrm{mL}$, and a control with no nanoparticles. Nanoparticles were sonicated before being added to the 12-well plate. The cells were incubated under standard conditions for one, 3 , or 6 days, washed with phosphate-buffered solution and stained with acridine orange (Sigma). Cells were visualized and counted by fluorescence microscopy.

\section{Cell viability assay}

The Cell Counting Kit-8 (CCK-8, Beyotime, China) was employed to evaluate quantitatively the viability of the osteoblasts, as described previously. ${ }^{22}$ Cell viability tests were conducted at 72 hours. Briefly, approximately 8000 cells were seeded in each well of a 96-well plate for 12 hours. Chitosan-coated and uncoated iron oxide nanoparticles $(20,100,300 \mu \mathrm{g} / \mathrm{mL})$ were added to separate wells and cocultured with osteoblasts. The cells were incubated under standard conditions $\left(37^{\circ} \mathrm{C}\right.$, humidified, $5 \% \mathrm{CO}_{2}$, $95 \%$ air) for 48 hours before being subjected to a CCK-8 assay. The culture medium was removed and the cultures were washed twice with phosphate-buffered solution. Approximately $100 \mu \mathrm{L}$ of serum-free Dulbecco's modified Eagle's medium and $10 \mu \mathrm{L}$ of CCK-8 solution were added to each well, and the plate was incubated at $37^{\circ} \mathrm{C}$ for 2 hours. The optical density at $450 \mathrm{~nm}$ was then determined in wells using a microplate reader (Bio-Tek Instrument Inc, Winooski, VT). Four duplicate samples were assayed for each time point.

\section{Lactate dehydrogenase assay}

A commercial lactate dehydrogenase kit (Cayman Chemical Company, Ann Arbor, MI) was used to measure lactate dehydrogenase activity in the culture medium. Lactate dehydrogenase is a soluble enzyme located in the cytosol. When apoptosis or necrosis occurs, lactate dehydrogenase is released into the surrounding culture medium. Lactate dehydrogenase activity is used for the measurement of cytotoxicity as an indicator of cell membrane integrity. After incubation with $200 \mu \mathrm{g} / \mathrm{mL}$ nanoparticles for 3 or 6 days, the lactate dehydrogenase activity in $100 \mu \mathrm{L}$ culture medium was assayed. The optical density at $490 \mathrm{~nm}$ was then determined using a microplate reader. All procedures were based on the protocols of the Cayman Chemical Company. 


\section{Total intracellular protein synthesis}

Osteoblasts were seeded on polystyrene substrates at a density of $10^{5}$ cells $/ \mathrm{cm}^{2}$ and cultured under standard conditions for 7, 14, or 21 days. Chitosan-coated and uncoated iron oxide nanoparticles $200 \mu \mathrm{g} / \mathrm{mL}$ were then added to the cultures. The medium was replaced every other day. At the end of each prescribed time period, the supernatant was removed and the substrates were washed three times with phosphate-buffered solution. The remaining osteoblasts were lysed using deionized water and three freezethaw cycles. ${ }^{23}$ The supernatant lysates were transferred to microtubes to determine intracellular protein synthesis. The total intracellular protein content in the cell lysates was determined using a commercially available kit (Pierce Chemicals, Rockford, IL) and a spectrophotometer, following the manufacturer's instructions. The absorbance at $595 \mathrm{~nm}$ of these samples was measured. Total protein synthesized by the osteoblasts was determined from a standard curve of absorbance versus known albumin concentrations that was run in parallel with the experimental samples. The total intracellular protein content was normalized to the osteoblast-exposed substrate area.

\section{Alkaline phosphatase activity assay}

Alkaline phosphatase is a marker of early-stage differentiation towards an osteoblast phenotype. Alkaline phosphatase activity increases as primary cells begin to differentiate towards the osteoblast phenotype, reaches its peak, and then decreases as cells mature into active osteoblasts. ${ }^{24}$ Osteoblasts were seeded on polystyrene substrates at a density of $10^{5} \mathrm{cells} / \mathrm{cm}^{2}$ for 12 hours at $37^{\circ} \mathrm{C}$. Chitosan-coated and uncoated iron oxide nanoparticles $(200 \mu \mathrm{g} / \mathrm{mL})$ were added to the cultures for 7, 14, or 21 days. At each time point, the cell layers were washed with phosphate-buffered solution, harvested using $0.25 \%$ trypsin-ethylenediamine tetraacetic acid, and protein was extracted with $1 \%$ Triton X-100 (Sigma). After centrifugation, alkaline phosphatase activity and total protein levels in the cell lysates were assayed by addition of $100 \mu \mathrm{L}$ of $p$-nitrophenylphosphate. The reaction was stopped after 30 minutes by addition of $50 \mu \mathrm{L}$ of $2 \mathrm{M}$ $\mathrm{NaOH}$. Absorbance at $405 \mathrm{~nm}$ of the samples was then measured with a spectrophotometer (Bio-Tek Instruments Inc) to quantify the amount of $p$-nitrophenol produced. A standard curve of absorbance versus $p$-nitrophenol concentration was generated and used to determine the $p$-nitrophenol concentration in the samples. Alkaline phosphatase activity values were normalized to total protein concentrations in the lysate. ${ }^{24,25}$

\section{Calcium deposition in extracellular matrix}

After 21 days of incubation with nanoparticles, osteoblast lysates were removed from the substrates, and the remaining extracellular matrix was treated with $0.6 \mathrm{M} \mathrm{HCl}$ at room temperature for 24 hours. Calcium levels in the acidic supernatants were quantified using a commercially available kit (Calcium Quantification Kit; Sigma), following the manufacturer's instructions. Absorbance of the samples at $575 \mathrm{~nm}$ was measured spectrophotometrically. Calcium levels $(\mu \mathrm{g} / \mathrm{L})$ were calculated from standard curves of absorbance versus known calcium concentrations measured in parallel with the experimental samples. Calcium concentrations were normalized to the substrate area and expressed as $\mu \mathrm{g} / \mathrm{cm}^{2}$. Experiments were repeated four times.

\section{Statistical analyses}

Data are expressed as the mean \pm the standard error of the mean. The results were analyzed using the Student's $t$-test, and $P$ values less than 0.05 were considered to be statistically significant.

\section{Results \\ Nanoparticle characterization}

TEM showed that most of the uncoated iron oxide nanoparticles were sphere-like, with diameters of 6-12 nm (Figure 1). Chitosan-coated iron oxide nanoparticles were very similar in shape but larger, with most nanoparticles showing diameters of 15-25 nm (Figure 2). The largest percentage of distribution size of these nanoparticles was $18 \mathrm{~nm}$, and that of the

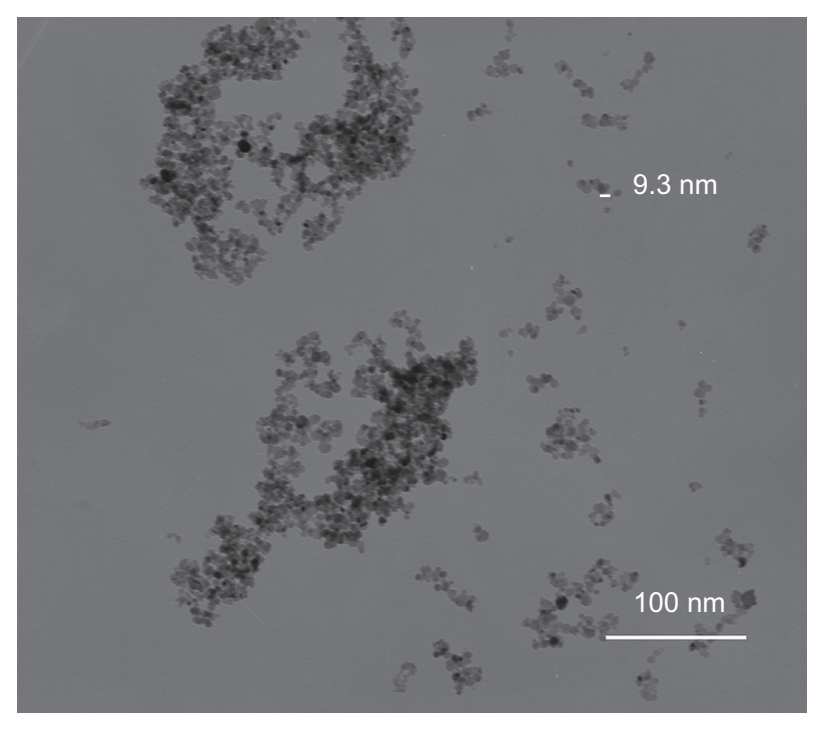

Figure I Transmission electron microscopic image of iron oxide nanoparticles. 


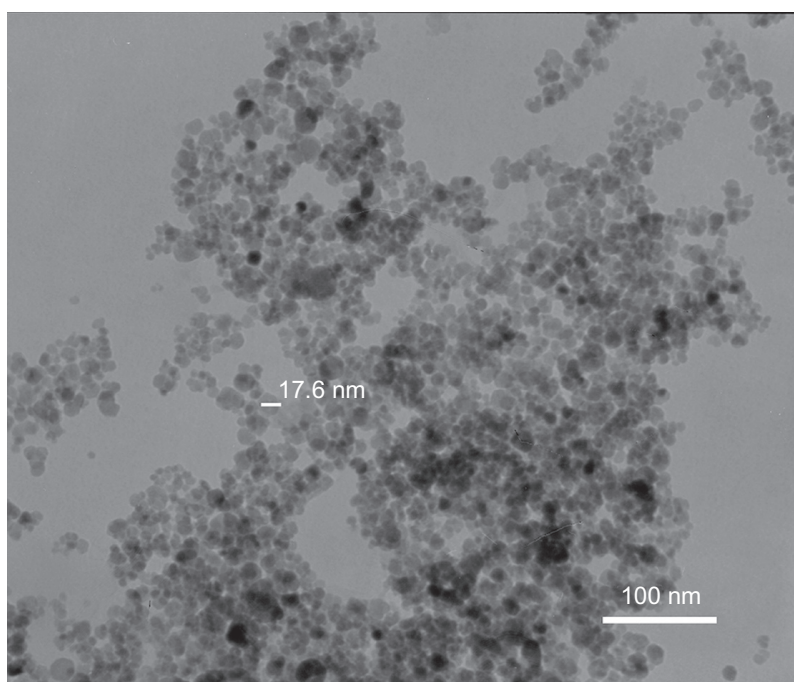

Figure 2 Transmission electron microscopic image of chitosan-coated iron oxide nanoparticles.

chitosan-coated iron oxide nanoparticles was $35 \mathrm{~nm}$ as measured by dynamic light scattering (Figure 3 ). The average zeta potential was $47.8 \mathrm{mV}$ (Figure 4). The x-ray diffraction pattern confirmed the existence of iron oxide in the final product (Figure 5). According to the vibrating sample magnetometry results, the chitosan-coated iron oxide nanoparticles showed properties of superparamagnetic materials (Figure 6).

\section{Interaction of osteoblasts with nanoparticles under TEM}

After incubation for 48 hours, uncoated iron oxide nanoparticles were observed within osteoblasts (Figure 7). There was an increased number of vacuoles in the cytoplasm, and the nanoparticles were localized mostly to osteoblast organelles. Karyopyknosis was observed in osteoblasts that contained a large number of iron oxide nanoparticles in the cytoplasm. In contrast, most chitosan-coated iron oxide nanoparticles

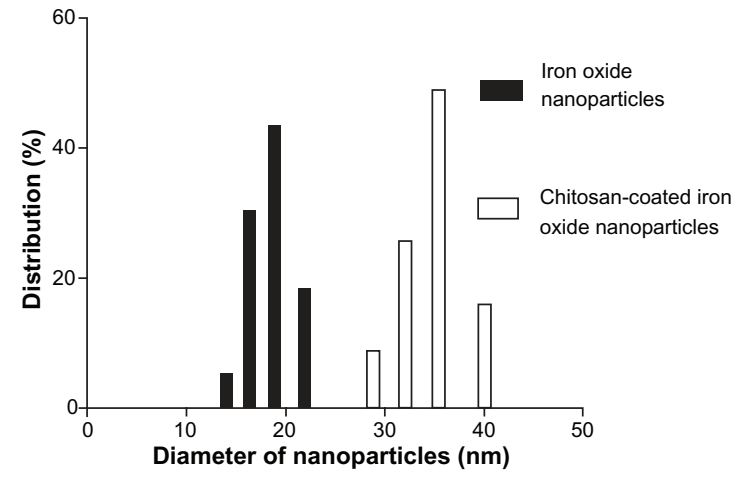

Figure 3 Particle size distribution of iron oxide nanoparticles and chitosan-coated iron oxide nanoparticles by dynamic light scattering.

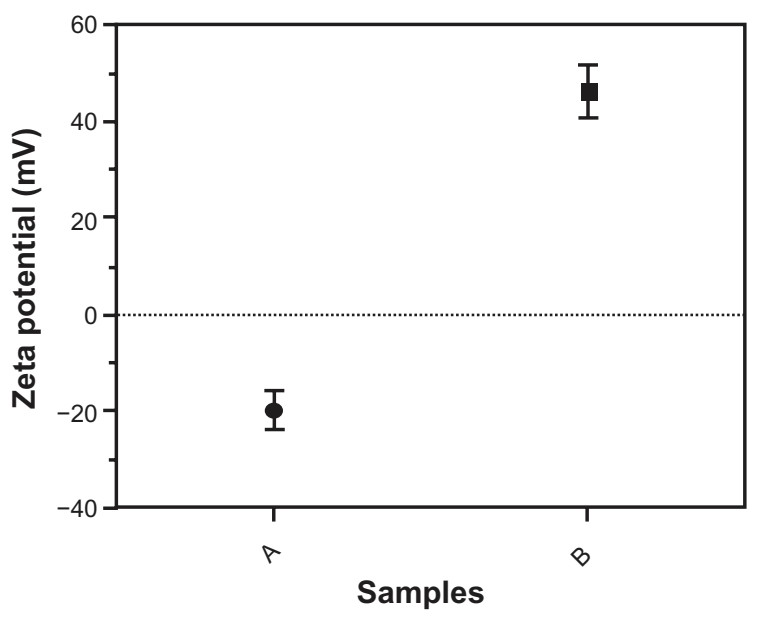

Figure 4 Zeta potential of nanoparticles by a Malvern Zetasizer Nano instrument. (A) Uncoated iron oxide nanoparticles and (B) chitosan-coated iron oxide nanoparticles.

were found outside cells, attached to the cell membrane (Figure 8). This was expected, because chitosan-coated iron oxide nanoparticles were larger and had a different surface charge than the iron oxide nanoparticles.

\section{Prussian blue staining}

Prussian blue staining indicated that chitosan-coated iron oxide nanoparticles had lower cellular uptake than did uncoated nanoparticles (Figure 9).

\section{Osteoblast proliferation}

After culture for one day, osteoblast densities were similar to that of the control. However, cell density increased significantly when cocultured with chitosan-coated iron oxide nanoparticles $(100 \mu \mathrm{g} / \mathrm{mL})$ after 3 and 6 days, compared with the control (Figure 10).

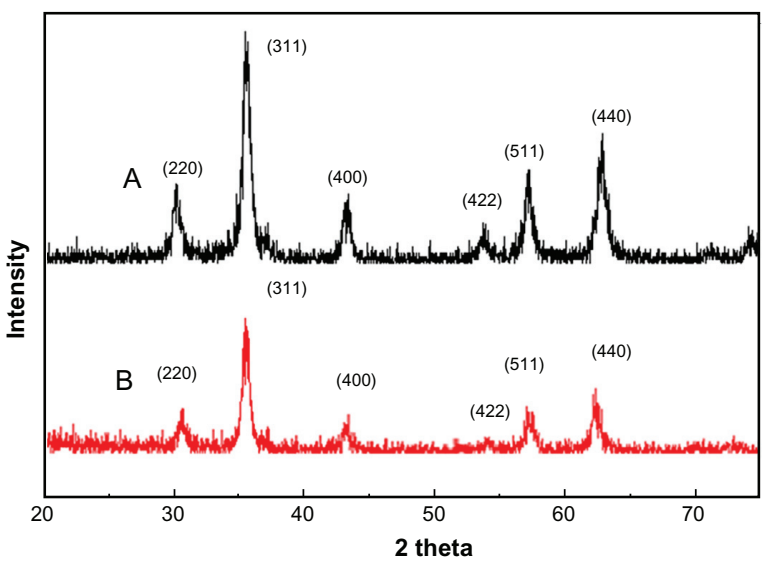

Figure 5 X-ray diffraction results for synthesized nanoparticles. (A) Iron oxide nanoparticles and (B) chitosan-coated iron oxide nanoparticles. 


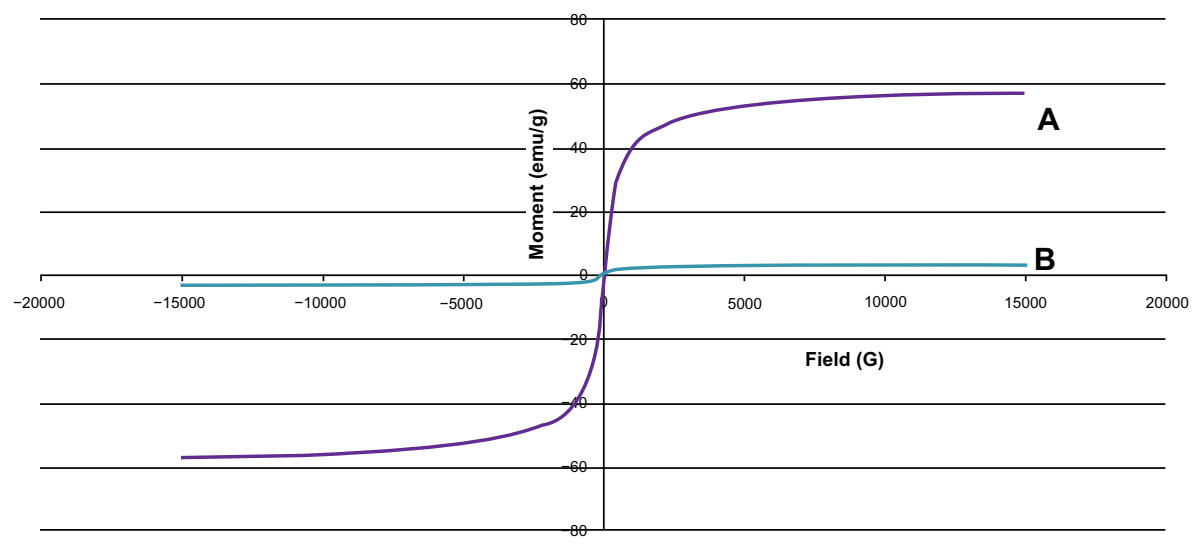

Figure 6 Magnetization curves of chitosan-coated iron oxide nanoparticles as measured by vibrating sample magnetometry at room temperature. (A) Iron oxide nanoparticles and (B) chitosan-coated iron oxide nanoparticles.

\section{Cell viability assay}

The CCK- 8 assay was used to compare the viability of SV40 osteoblasts after 48 hours of incubation with iron oxide or chitosan-coated nanoparticles $(20,100$, and $300 \mu \mathrm{g} / \mathrm{mL})$. As shown in Figure 11, the osteoblast viability was not significantly different when the concentration of chitosan-coated nanoparticles increased from $20 \mu \mathrm{g} / \mathrm{mL}$ to $300 \mu \mathrm{g} / \mathrm{mL}$ when cocultured with chitosan-coated nanoparticles. However, decreased osteoblast viability was shown as the concentration increased from $100 \mu \mathrm{g} / \mathrm{mL}$ to $300 \mu \mathrm{g} / \mathrm{mL}$ when cocultured with iron oxide nanoparticles. Moreover, osteoblasts incubated with chitosan-coated nanoparticles showed higher osteoblast viability than uncoated nanoparticles at concentrations of $100 \mu \mathrm{g} / \mathrm{mL}$ and $300 \mu \mathrm{g} / \mathrm{mL}$. This may have been due to internalization of more nanoparticles, resulting in apoptosis as shown by TEM.

\section{Lactate dehydrogenase assay}

The lactate dehydrogenase assay is a convenient method for evaluation of cell damage, as indicated by lactate dehydrogenase release from the cytosol of lysed cells. The lactate

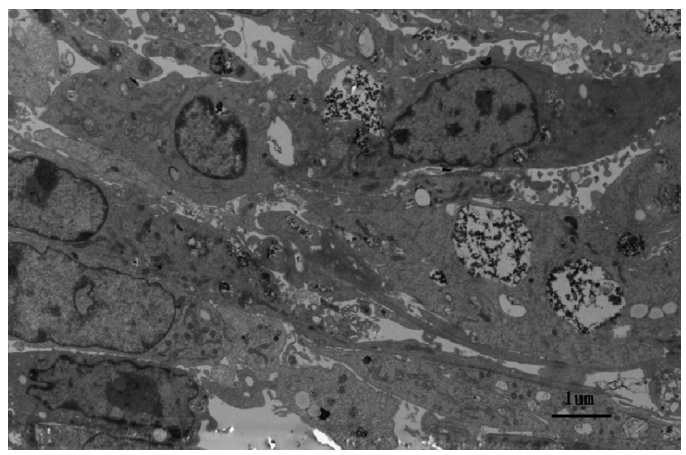

Figure 7 Transmission electron micrographs of $\mathrm{Fe}_{3} \mathrm{O}_{4}$ nanoparticle uptake by osteoblasts. dehydrogenase results (Figure 12) were consistent with those of the CCK-8 assay. There was no significant difference between the iron oxide and the control groups. However, the absorbance values of the chitosan-coated iron oxide nanoparticles were much lower than those of the controls, suggesting less cell membrane damage.

\section{Total intracellular protein}

Total intracellular protein levels are shown in Figure 13. After 7,14 , and 21 days, intracellular protein levels of osteoblasts incubated with chitosan-coated iron oxide nanoparticles were higher than those of both osteoblasts incubated with uncoated iron oxide nanoparticles and the control at each time point. There was no significant difference in intracellular protein levels in osteoblasts incubated with uncoated iron oxide nanoparticles compared with the control after 14 and 21 days.

\section{Alkaline phosphatase activity assay}

Chitosan-coated magnetic nanoparticles $200 \mu \mathrm{g} / \mathrm{mL}$ showed significantly higher alkaline phosphatase activity compared with the control after 7 and 14 days (Figure 14). Coculture with

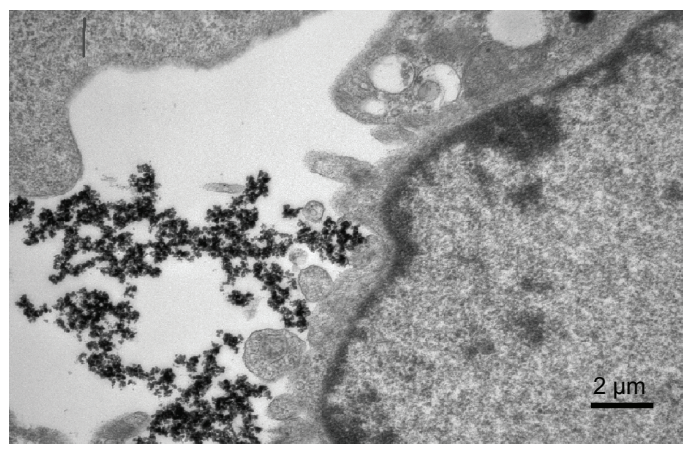

Figure 8 Transmission electron micrographs of chitosan-coated $\mathrm{Fe}_{3} \mathrm{O}_{4}$ nanoparticles attached to cell surfaces. 

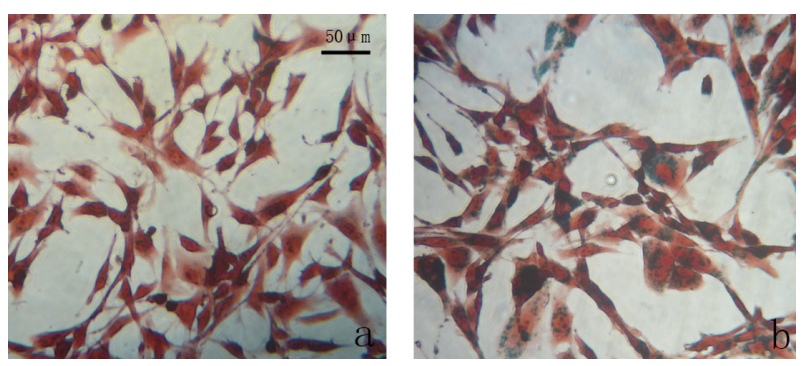

Figure 9 Prussian blue staining of iron in osteoblasts. Osteoblast SV40 incubated with chitosan-coated iron oxide nanoparticles (A) and uncoated iron oxide nanoparticles (B) at a concentration of $200 \mu \mathrm{g} / \mathrm{mL}$ for 24 hours.

Note: Scale bar $50 \mu \mathrm{m}$.

chitosan-coated magnetic nanoparticles resulted in significantly enhanced alkaline phosphatase activity at all time points compared with iron oxide nanoparticle coculture. This may have been due to induction of apoptosis and necrosis by the large number of nanoparticles internalized in osteoblasts.

\section{Extracellular calcium deposition}

Calcium deposition by osteoblasts on culture plates was detected after 21 days of culture (Figure 15). Generally, significantly higher amounts of calcium were deposited by osteoblasts when incubated with chitosan-coated iron oxide nanoparticles compared with the control. More calcium deposition was shown at the concentration of $300 \mu \mathrm{g} / \mathrm{mL}$ than $20 \mu \mathrm{g} / \mathrm{mL}$ when incubated with chitosan-coated nanoparticles. However, this was not the case in the uncoated nanoparticle group.

\section{Discussion}

In this study, we created chitosan-coated iron oxide nanoparticles to establish new approaches to treatment of low bone mineral density (such as osteoporosis and the loosening of prostheses) and to develop a new drug delivery system for

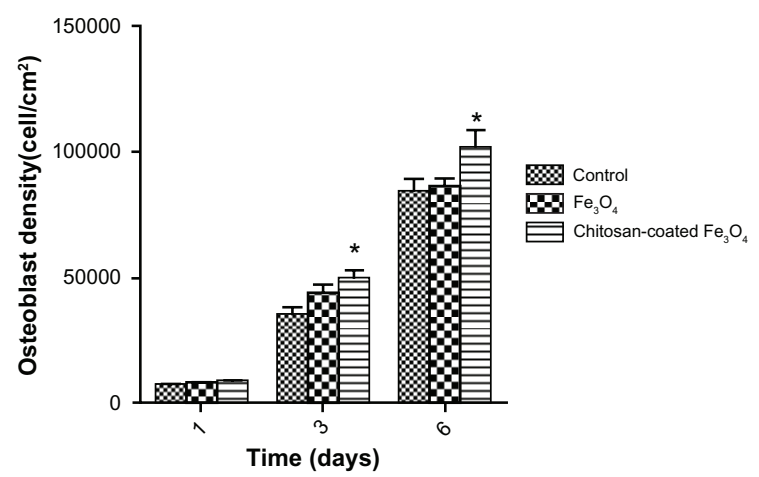

Figure 10 Osteoblast density in the presence of magnetic nanoparticles after one, 3 , and 6 days of culture.

Notes: Nanoparticle concentration was $100 \mu \mathrm{g} / \mathrm{mL}$. Data are shown as the mean \pm standard error of the mean $(n=4)$. $* P<0.05$ compared with control samples.

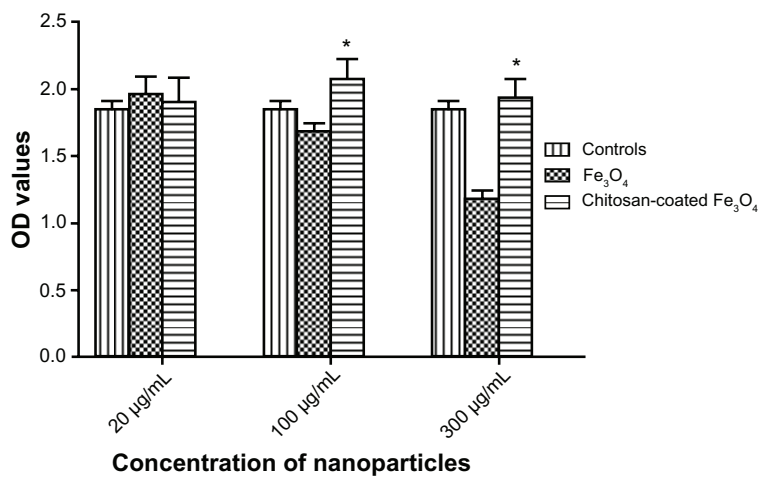

Figure I I Cell viability of SV40 osteoblasts incubated with different concentrations of nanoparticles after 3 days.

Notes: Data are shown as the mean \pm standard error of the mean $(n=4)$. $* P<0.05$ compared with the $\mathrm{Fe}_{3} \mathrm{O}_{4}$ group.

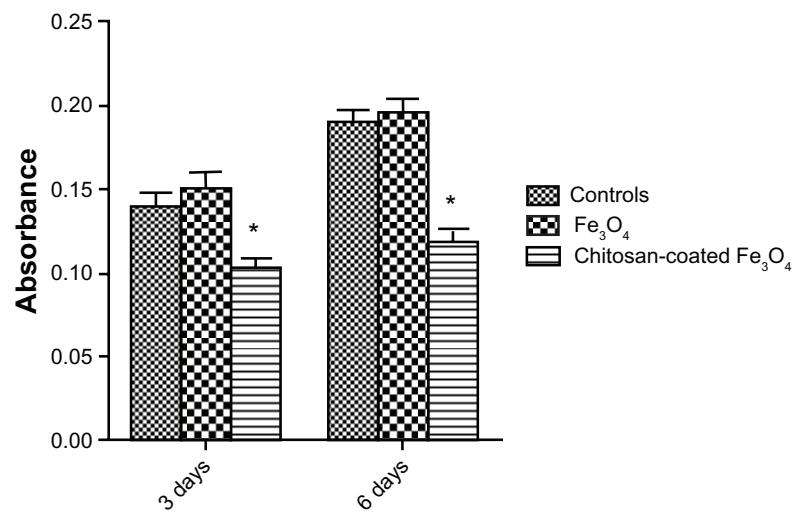

Figure 12 Lactate dehydrogenase assay of osteoblasts incubated with chitosancoated iron oxide nanoparticles and iron oxide nanoparticles $(200 \mu \mathrm{g} / \mathrm{mL})$ for 3 days and 6 days.

Notes: Data are shown as the mean \pm standard error of the mean $(n=4) . * P<0.05$ compared with control samples.

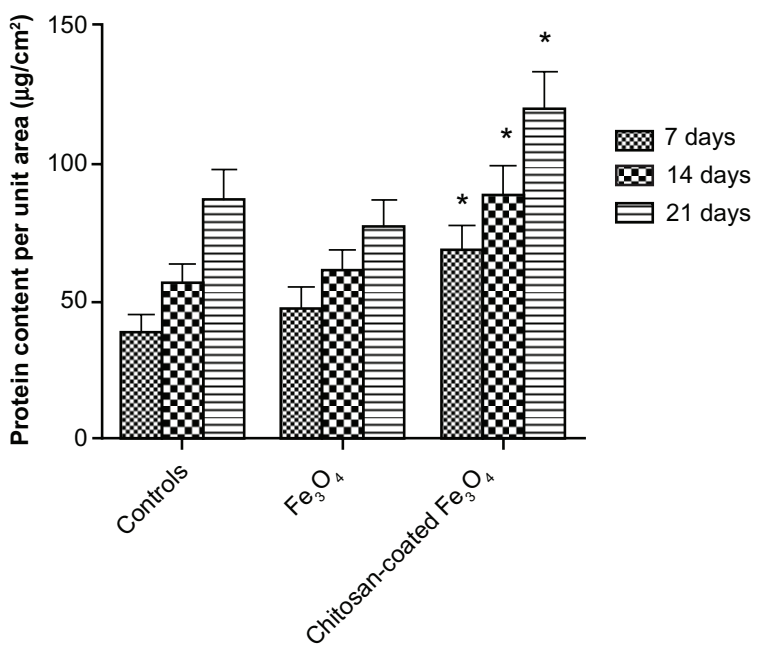

Figure 13 Intracellular total protein synthesis of osteoblasts incubated with chitosan-coated iron oxide nanoparticles and iron oxide nanoparticles $(200 \mu \mathrm{g} / \mathrm{mL})$ for 7,14 , and 21 days.

Notes: Data are shown as the mean \pm standard error of the mean $(n=4)$. $* P<0.05$ compared with control samples. Osteoblast seeding density was $100,000 \mathrm{cells} / \mathrm{cm}^{2}$. 


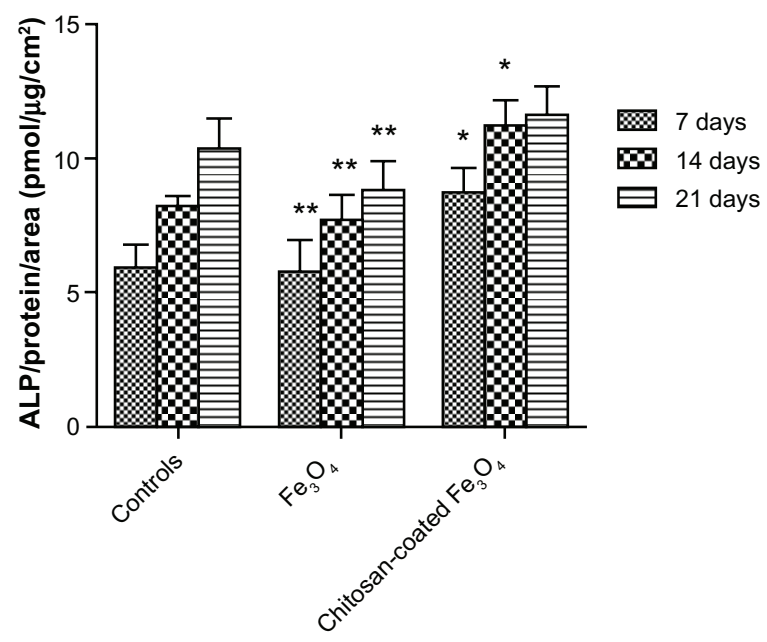

Figure I4 Alkaline phosphatase activity of osteoblasts after 7, 14, and 21 days of culture.

Notes: Data are shown as the mean \pm standard error of the mean $(n=4) . * P<0.05$ compared with control samples at the same time point; $* * P<0.05$ compared with the chitosan-coated nanoparticles at the same time point.

orthopedic applications. Using an external magnetic field, these magnetic nanoparticles can be directed to the desired site of bone formation. The nanoparticle is a core-shell material; it is a combination of magnetically controllable iron oxide and the cytocompatible material chitosan, resulting in a targetable therapeutic. In the present study, chitosan-coated iron oxide nanoparticles promoted cell proliferation and enhanced several important osteoblast markers of differentiation, including alkaline phosphatase activity and calcium deposition.

Surface treatments, including improvement of surface chemistry, surface energy, and surface topography, enhance

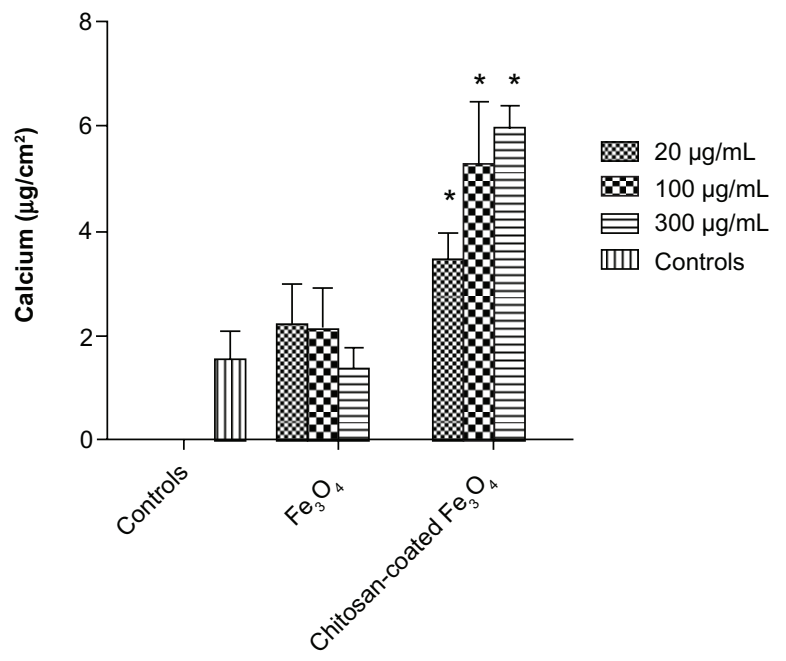

Figure 15 Extra cellular calcium deposition in the presence of nanoparticles of different concentrations after 21 days of culture.

Notes: Data are shown as the mean \pm standard error of the mean $(n=4) .{ }^{*} p<0.05$ compared with control samples at the same time point. osteoblast responses. ${ }^{23,26}$ Of these, the contribution of surface topography is the greatest. ${ }^{23}$ Surface nanocrystallization has been shown to optimize the surface topography, ${ }^{27}$ and research has demonstrated its enhancement of osteoblast adhesion, proliferation, and differentiation. ${ }^{28}$ Chitosan-coated nanoparticles have a large surface area to volume ratio, which benefits osteoblast adhesion. Adhesion of chitosan-coated nanoparticles to the cell membrane was observed by TEM in this study.

Also, the majority of the chitosan-coated iron oxide nanoparticles was extracellular and attached to the membrane, while the uncoated nanoparticles were predominantly intracellular. Tran and Webster attributed this phenomenon to the different particle sizes, and our results were consistent with these findings. ${ }^{23}$ However, it is also possible that surface charge contributes to this phenomenon. Osaka et al reported a correlation between surface charge and cellular uptake efficiency into different cell lines..$^{29}$ Nanoparticles with a positive charge have been shown to have a higher internalization rate in human breast cancer cells compared with those with a negative charge. However, the degrees of internalization of positively charged and negatively charged nanoparticles into human umbilical vein endothelial cells were similar. Chitosan coating alters the surface charge of iron oxide nanoparticles..$^{30-32}$

Coculture with chitosan-coated iron oxide nanoparticles increased osteoblast proliferation, viability, and differentiation. The mechanisms underlying these effects are still under investigation. Mathews et al found that chitosan enhanced mineralization significantly during osteoblast differentiation of human bone marrow-derived mesenchymal stem cells by upregulating the expression of associated genes, such as collagen type 1 alpha 1, integrin-binding sialoprotein, osteopontin, osteonectin, and osteocalcin. ${ }^{14}$ Another plausible hypothesis is that protein adsorption on nanophase surfaces and nanoparticles differs from that on conventional surfaces. ${ }^{14}$ Adhesive dots less than $73 \mathrm{~nm}$ in diameter improved cell attachment and spreading, and dramatically increased the formation of focal adhesion and actin stress fibers. ${ }^{33}$ Webster et al showed that in the serum environment, there was increased vitronectin adsorbed to nanophase surfaces of alumina. ${ }^{34}$ Vitronectin is considered to be a significant protein important for osteoblast adhesion. ${ }^{33}$

Iron oxide nanoparticles showed satisfactory cytocompatibility at low concentrations. It has been postulated that interactions between the nanoparticle charges on the cell surface may enhance the metabolic activity of the cell. ${ }^{15,35}$ However, as the concentration increased to $300 \mu \mathrm{g} / \mathrm{mL}$, cytotoxicity was shown in terms of both proliferation and differentiation. This may have been due to the increased internalization of iron 
oxide nanoparticles by osteoblasts, which induced apoptosis. This phenomenon was also observed by TEM. However, no concentration-dependent internalization of chitosan-coated nanoparticles was observed, and this is the desired result, given that there will be less dosage restrictions in clinical practice.

The aim of this study was to facilitate understanding of the use of magnetic nanoparticles for the treatment of osteoporosis and loosening of prostheses. Furthermore, chemotherapeutic compounds (eg, antibiotics) can be loaded into chitosan-coated nanoparticles; the magnetic properties of these nanoparticles can be utilized to target the infective focus, resulting in a high drug concentration at the appropriate site. Thus, the success of such a treatment requires that the particles are cytocompatible with osteoblasts. Therefore, it is encouraging that our data suggest chitosan-coated iron oxide nanoparticles have satisfactory proliferative and differential effects on osteoblasts. These results are promising, but further in vivo and in vitro investigations of the efficacy and safety of magnetic nanoparticles are necessary to optimize their use in various orthopedic applications.

\section{Conclusion}

Uncoated and chitosan-coated iron oxide nanoparticles were synthesized and characterized by TEM, dynamic light scattering, x-ray diffraction, zeta potential, and vibrating sample magnetometry. Osteoblast proliferation, viability, and differentiation were assayed in the presence of uncoated and chitosancoated iron oxide nanoparticles. The results indicate that chitosan-coated iron oxide nanoparticles enhanced osteoblast viability. Most importantly, coculture of chitosan-coated nanoparticles with osteoblasts showed improved differentiation, as indicated by higher alkaline phosphatase activity and extracellular calcium deposition compared with the controls. These data suggest the potential of chitosan-coated magnetic nanoparticles to increase bone growth at bone defect sites, and this should be the subject of further research.

\section{Acknowledgment}

This work was supported by the Interdisciplinary (Medical Engineering) Research Fund of Shanghai Jiao Tong University (YG2011MS30).

\section{Disclosure}

The authors declare no conflicts of interest in this work.

\section{References}

1. Sanchez-Riera L, Wilson N, Kamalaraj N, et al. Osteoporosis and fragility fractures. Best Pract Res Clin Rheumatol. 2010;24(6):793-810.
2. Becker DJ, Kilgore ML, Morrisey MA. The societal burden of osteoporosis. Curr Rheumatol Rep. 2010;12(3):186-191.

3. Dempster DW. Osteoporosis and the burden of osteoporosis-related fractures. Am J Manag Care. 2011;17 Suppl 6:S164-S169.

4. Ascenzi MG, Liao VP, Lee BM, et al. Parathyroid hormone treatment improves the cortical bone microstructure by improving the distribution of type I collagen in postmenopausal women with osteoporosis. $J$ Bone Miner Res. 2012;27(3):702-712.

5. Kraenzlin ME, Meier C. Parathyroid hormone analogues in the treatment of osteoporosis. Nat Rev Endocrinol. 2011;7(11):647-656.

6. Shen L, Xie X, Su Y, Luo C, Zhang C, Zeng B. Parathyroid hormone versus bisphosphonate treatment on bone mineral density in osteoporosis therapy: a meta-analysis of randomized controlled trials. PLoS One. 2011;6(10): 26267.

7. Seeman E, Eisman JA. Treatment of osteoporosis: why, whom, when and how to treat. The single most important consideration is the individual's absolute risk of fracture. Med J Aust. 2004;180(6):298-303.

8. Pareta RA, Taylor E, Webster TJ. Increased osteoblast density in the presence of novel calcium phosphate coated magnetic nanoparticles. Nanotechnology. 2008;19(26):265101.

9. Adami S, Zamberlan N. Adverse effects of bisphosphonates. A comparative review. Drug Saf. 1996;14(3):158-170.

10. Polyak B, Friedman G. Magnetic targeting for site-specific drug delivery: applications and clinical potential. Expert Opin Drug Deliv. 2009;6(1):53-70.

11. Voltairas PA, Fotiadis DI, Michalis LK. Hydrodynamics of magnetic drug targeting. J Biomech. 2002;35(6):813-821.

12. Alexiou C, Jurgons R, Schmid RJ, et al. Magnetic drug targeting biodistribution of the magnetic carrier and the chemotherapeutic agent mitoxantrone after locoregional cancer treatment. J Drug Target. 2003;11(3):139-149.

13. Jones GL, Motta A, Marshall MJ, El Haj AJ, Cartmell SH. Osteoblast: osteoclast co-cultures on silk fibroin, chitosan and PLLA films. Biomaterials. 2009;30(29):5376-5384.

14. Mathews S, Gupta PK, Bhonde R, Totey S. Chitosan enhances mineralization during osteoblast differentiation of human bone marrow-derived mesenchymal stem cells, by upregulating the associated genes. Cell Prolif. 2011;44(6):537-549.

15. Heinemann C, Heinemann S, Bernhardt A, Worch H, Hanke T. Novel textile chitosan scaffolds promote spreading, proliferation, and differentiation of osteoblasts. Biomacromolecules. 2008;9(10):2913-2920.

16. Cai K, Hu Y, Jandt KD, Wang Y. Surface modification of titanium thin film with chitosan via electrostatic self-assembly technique and its influence on osteoblast growth behavior. J Mater Sci Mater Med. 2008;19(2):499-506.

17. Shi C, Zhu Y, Ran X, Wang M, Su Y, Cheng T. Therapeutic potential of chitosan and its derivatives in regenerative medicine. J Surg Res. 2006;133(2):185-192.

18. Zhu XM, Wang YX, Leung KC, et al. Enhanced cellular uptake of aminosilane-coated superparamagnetic iron oxide nanoparticles in mammalian cell lines. Int J Nanomedicine. 2012;7:953-964.

19. Mou Y, Hou Y, Chen B, et al. In vivo migration of dendritic cells labeled with synthetic superparamagnetic iron oxide. Int $J$ Nanomedicine. 2011;6:2633-2640.

20. Li Y, Yao Y, Sheng Z, Yang Y, Ma G. Dual-modal tracking of transplanted mesenchymal stem cells after myocardial infarction. Int $J$ Nanomedicine. 2011;6:815-823.

21. Chen R, Yu H, Jia ZY, Yao QL, Teng GJ. Efficient nano iron particlelabeling and noninvasive MR imaging of mouse bone marrow-derived endothelial progenitor cells. Int J Nanomedicine. 2011;6:511-519.

22. Wang L, Wang ZH, Shen CY, You ML, Xiao JF, Chen GQ. Differentiation of human bone marrow mesenchymal stem cells grown in terpolyesters of 3-hydroxyalkanoates scaffolds into nerve cells. Biomaterials. 2010;31(7):1691-1698.

23. Tran N, Webster TJ. Increased osteoblast functions in the presence of hydroxyapatite-coated iron oxide nanoparticles. Acta Biomater. 2011;7(3):1298-1306. 
24. Zhang Y, Shi B, Li C, et al. The synergetic bone-forming effects of combinations of growth factors expressed by adenovirus vectors on chitosan/ collagen scaffolds. J Control Release. 2009;136(3):172-178.

25. Haidar ZS, Azari F, Hamdy RC, Tabrizian M. Modulated release of OP-1 and enhanced preosteoblast differentiation using a core-shell nanoparticulate system. J Biomed Mater Res A. 2009;91(3):919-928.

26. Zhao G, Schwartz Z, Wieland M, et al. High surface energy enhances cell response to titanium substrate microstructure. J Biomed Mater Res A. 2005;74(1):49-58.

27. Khang D, Lu J, Yao C, Haberstroh KM, Webster TJ. The role of nanometer and sub-micron surface features on vascular and bone cell adhesion on titanium. Biomaterials. 2008;29(8):970-983.

28. Price RL, Ellison K, Haberstroh KM, Webster TJ. Nanometer surface roughness increases select osteoblast adhesion on carbon nanofiber compacts. J Biomed Mater Res A. 2004;70(1):129-138.

29. Osaka T, Nakanishi T, Shanmugam S, Takahama S, Zhang H. Effect of surface charge of magnetite nanoparticles on their internalization into breast cancer and umbilical vein endothelial cells. Colloids Surf B Biointerfaces. 2009;71(2):325-330.
30. Ortega D, Velez-Fort E, Garcia DA, et al. Size and surface effects in the magnetic properties of maghemite and magnetite coated nanoparticles. Philos Transact A Math Phys Eng Sci. 2010;368(1927):4407-4418.

31. Selvan ST. Silica-coated quantum dots and magnetic nanoparticles for bioimaging applications. Biointerphases. 2010;5(3):FA110-FA115.

32. Nam HY, Kwon SM, Chung H, et al. Cellular uptake mechanism and intracellular fate of hydrophobically modified glycol chitosan nanoparticles. J Control Release. 2009;135(3):259-267.

33. Webster TJ, Ergun C, Doremus RH, Siegel RW, Bizios R. Specific proteins mediate enhanced osteoblast adhesion on nanophase ceramics. J Biomed Mater Res. 2000;51(3):475-483.

34. Webster TJ, Schadler LS, Siegel RW, Bizios R. Mechanisms of enhanced osteoblast adhesion on nanophase alumina involve vitronectin. Tissue Eng. 2001;7(3):291-301.

35. Ma J, Wang H, He B, Chen J. A preliminary in vitro study on the fabrication and tissue engineering applications of a novel chitosan bilayer material as a scaffold of human neofetal dermal fibroblasts. Biomaterials. 2001;22(4):331-336.
International Journal of Nanomedicine

\section{Publish your work in this journal}

The International Journal of Nanomedicine is an international, peerreviewed journal focusing on the application of nanotechnology in diagnostics, therapeutics, and drug delivery systems throughout the biomedical field. This journal is indexed on PubMed Central, MedLine, CAS, SciSearch $\AA$, Current Contents ${ }^{\circledR} /$ Clinical Medicine,

\section{Dovepress}

Journal Citation Reports/Science Edition, EMBase, Scopus and the Elsevier Bibliographic databases. The manuscript management system is completely online and includes a very quick and fair peer-review system, which is all easy to use. Visit http://www.dovepress.com/ testimonials.php to read real quotes from published authors. 